\title{
Integrative cities: when art and architecture become strategic
}

\author{
D. Huertas Nadal \\ Department of Architecture, University UFV Madrid, Spain
}

\begin{abstract}
Building the 21st century city requires creativity and flexibility in the face of rapid change and scarce resources. Thus, in the "the Urban Age", approximately $50 \%$ of the world's population lives in cities $33 \%$ of which, some 827 million people, live in informal settlements (UNHABITAT report 2010/2011). Recent European research has focused on the unplanned architecture of urban slums worldwide. One source of optimism for architects and artists lies in informal communities. Increasingly, and particularly in Latin America, informality is no longer viewed as a design problem so much as a condition offering its own solutions. The so-called informal city, arising from informal settlements, alongside the formal city, provides a complex and fascinating territory. Relations between the two are critical as is the need to formalize integration processes. The formal city plans, legalizes, before constructing. The informal city invades, occupies, inhabits, builds, and only ultimately seeks to legalize. In order to define an inclusive city, how these dynamics overlap must be addressed.

Strategic projects, improving accessibility, services, and introducing formal city facilities and infrastructure to the informal city, raise unexpected, complex and interesting processes, far more effective than those of large-scale urban plans. Like acupuncture, such projects activate the city's energy points, proposing alternatives to large-scale centralized planning, based on the belief that minimal local intervention will provide the impetus for self organization.

Keywords: urban strategies, inclusive cities, networks, public space, informal city, right to the city, identity areas, social engagement.
\end{abstract}

\section{Introduction}

When tackling strategic projects for developing inclusive cities it is necessary to imagine, document, and manage in a creative way the new public space that is 
the contemporary city. One of the most critical situations arises from those areas excluded from the contemporary city and which are customarily defined as fourth worlds, namely those which lacking protection or at social risk in areas which are part of the first world. These fourth worlds are the initial focus of the project's work as they are areas which are constantly left out of any analyses of action plans. These places contain all the possibilities and all the conflicts which the Global Village typically brings, and thus they require an effective process of visualisation, analysis and management.

\section{Recent news: the urban era}

Contemporary urban development continues to be the driving force underlying global demographic change, despite the fact that it is happening at different rates in different parts of the world. The processes of sub-urbanisation and urban expansion are developing models of low urban density. This urban expansion in deprived areas further exacerbates the gap between the formal and the informal city, which has given rise to a worrying division of physical and social space in the global city.

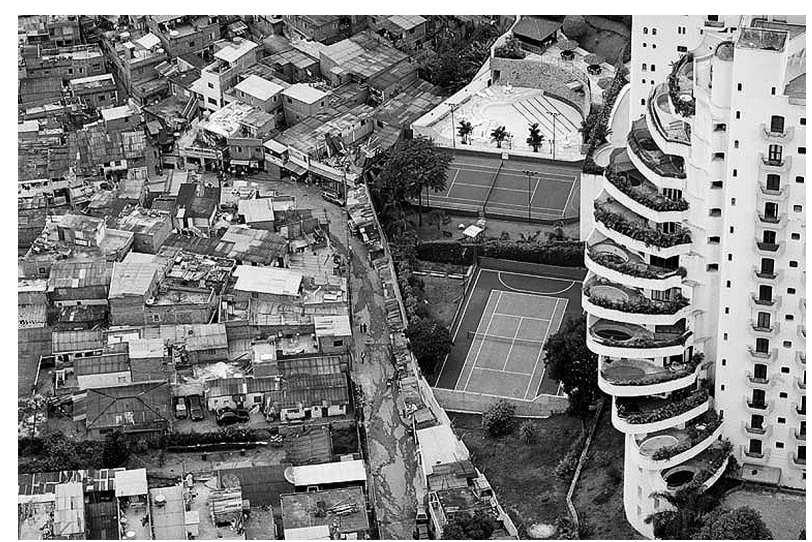

Figure 1: Sao Paulo, Tuca Vieira.

In 2010, there were around three thousand million people living in the world's cities, which amounts to most of the global population. Clearly we are currently experiencing an essentially urban era. As a result the 21 st century is considered in circles and forums concerned with the City to be the "era of cities" in which a growing percentage of the world's population will live in a metropolis. This urbanisation process is taking place at an alarming rate and with a scale, diversity, complexity and level of connectivity which challenges all the traditional paradigms and which renders many conventional tools and most of the professional practices in this area somewhat obsolete.

The world is inexorably becoming an urban place. By 2030 all the developing regions such as Asia and Africa, will have more people living in urban areas than 
in a rural setting. Thus in the next 20 years Homo sapiens, "wise man", will become Urbanus Homo sapiens in almost every part of the planet. By the mid twentieth century three out of every 10 people lived in cities. Today half the world's population live in urban areas and it is estimated that by the middle of this century all the regions of the planet will be predominantly urban. According to current forecasts, almost all the growth of the world's population in the next 30 years will be concentrated in metropolitan areas. We also know that in the last 10 years the proportion of urban population living in shanty towns within the developed world has been reduced from $39 \%$ in 2000 to an estimated rate of $32 \%$ by 2010 . And yet the division between the so called formal City and the informal City remains, as in absolute terms the number of inhabitants of marginal neighbourhoods has grown considerably and will continue to increase in the immediate future. UN-HABITAT estimates that through restructuring or prevention of informal settlements, developing countries were able to move approximately 22 million people out of substandard housing conditions between 2000 and 2010. Despite these efforts, the world population of shanty towns is expected to reach 889 million people by 2020 [1].

Notwithstanding this fact, although cities show a marked ability to innovate and experiment, and despite the energy and capacity for change in processes, the promise inherent in cities is systematically undermined. The quality of urban life has become a commodity, like the city itself, in a world in which consumerism, tourism, cultural and knowledge industries have become essential aspects of the political urban economy. Within this future framework, we are increasingly living in urban areas which are divisive and prone to conflict [2]. The city is something more, and should in fact be a great deal more, than those 700 million homeless people that the UNO claims are thus stigmatised in its Global Report on Urban Settlements; and the city is so much more than urban development speculation, construction chaos, neurosis or violence. The city according to urban sociologist Robert Parker, should be: "man's most successful attempt to remake the world he lives in according to his heart's desire. However, if the city is the world that man has created, it is also the world in which he is now condemned to live. Thus, indirectly and without a clear sense of the nature of its task in making the city, the human race is remaking itself" [3]. In this context the right to the city claimed by David Harvey makes sense [4]. The right to the city is much more than the individual freedom to access urban resources; it is the right to change ourselves by changing the city. It is furthermore, a communal right rather than an individual one, as this transformation depends inexorably on the exercise of a collective power in order to remodel urban development processes. There is a clear link between the challenges of the urban era and our current framework of urban solutions. There is a failure to connect policies designed to promote environmental sustainability with policies designed to reduce poverty. There is a failure to connect the complexity of the challenges raised with the predominant responses of urban policy. There is a failure to connect the artificial geography of government with the real economic and environmental footprint. 
Establishing links between policies should be the norm rather than the exception, reinforced by incentives and new structures and systems. We need to focus on co-production in all disciplines and professions. It is essential to transform vertical processes imposed by bureaucracies of the last century in order to set dynamics for horizontal, integrative and multidisciplinary action.

\section{New geographies: the informal city}

Estudio Teddy Cruz Having studied land use in this suburban zone, the Teddy Cruz studio in collaboration with the NGO Casa Familiar decided to create a complex housing system with a shared space which would permit recognition and exploitation of the development of numerous, dense and often illegal activities in this area. In a radically pragmatic and integrative approach Cruz has endeavoured to comprehend the neighbourhood structure and to create projects which will strengthen the community.

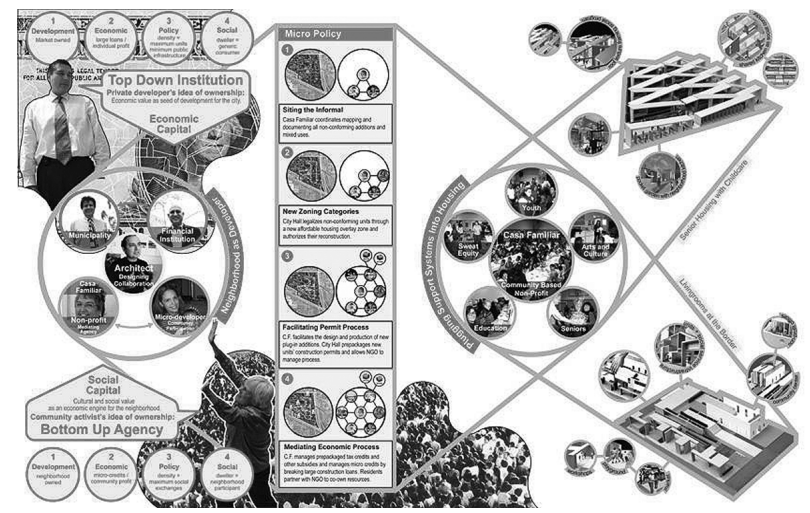

Figure 2: $\quad$ San Ysidro project, San Diego/Tijuana.

What does "the informal" or the idea of "informal" mean? Despite the familiarity with which we use the term - "the informal", and by extension, the Informal City, the informal has been defined in a number of ways. It is that which remains beyond the margins of the official, legal or planned, however even though it may often be illegal it is not necessarily synonymous with criminality. Illegal settlements of squatters are spread throughout the globe and are known as informal settlements because they do not form part of official plans. Robert Neuwirth in his recent book Shadow Cities: a billion squatters, a new urban world, describes squatters as new immigrants to the city who build their homes with their bare hands on land which does not belong to them. We are talking about one thousand million people living in irregular settlements who, having come to the city in search of work needed somewhere to live, and as they were unable to pay the going rates in the rental market they built their own homes on land over which they held no title whatsoever. These informal settlements create an enormous hidden economy, a complex unofficial system of 
dynamics between owner occupiers and illegal tenants and between illegal traders and squatter consumers, between illegal builders and casual workers, between investors and illegal entrepreneurs. The builders of informal housing are the biggest building constructors in the world and in one way play a part in formalising cities of the future [5].

The conventional definition of "informal" that is unofficial, illegal or unplanned, does not permit employment activities in their place of origin and nor is it possible for people to find homes in the areas where they are seeking work. There is no question that the growth of cities in the future depends on the success of planning capability and management of unplanned processes.

In the Latin American metropolis for example, the so called informal city, built on informal settlements which have grown up outside the confines of urban planning, occupy a considerable portion of urban space. Alongside the formal city a complex territory arises where the formal and the informal overlap in an urban scenario which it is difficult to programme and in which taking any type of action can prove particularly complicated. Here there is another geography at work, often concealed from the view of many of its citizens albeit slums, informal settlements, favelas or temporary squats. From Buenos Aires, Bogotá or Río to Los Angeles, Shanghai, Mumbai or Kibera.

In this regard, Marcello Balbo points out that "in the developing world in particular, the city is becoming divided into separate parts, a fact which inevitably leads to the formation of innumerable "microstates". Wealthy neighbourhoods which enjoy numerous and varied services such as exclusive schools, golf courses and tennis courts, and private policing and surveillance services which permanently control the area are interspersed with illegal settlements where the only water source is the public fountain and where there is no sewage or drainage system, where electricity is pirated by a privileged few, where the streets become a mudslide when it rains and where house sharing is the norm. Each segment of the population appears to live and function autonomously, clinging tenaciously to everything that they have managed to achieve in the daily struggle to survive" [6].

These are geographies of centrality and marginality. Urban centres and business districts receive considerable investment in the form of basic amenities and telecommunications, with Shanghai as a case in point, albeit an extreme example, while at the same time the poorer low income urban and metropolitan areas are deprived of resources, at times in a controlled manner as has happened in some areas of Brooklyn in New York and occasionally in a dramatic manner as in the Balibago, settlements in Los Angeles, or the shanty towns of Mexico City. The informal takes on new meaning in this context, offering an increasingly wide range of economic, artistic and professional practices in these cities, and whereas informality may be a form of injustice and impotence, it can also lead to the development of new survival economics and new models of creativity. In all cities of the Global Era from Mexico to Berlin, the informal economy is not only in expansion but it is also diversifying.

In contrast to the formal city, the informal city invades, occupies, inhabits, constructs, applies pressure and only finally does it attempt to legalise. The 
formal city legalises first and then constructs. Informal procedures and settlements rather than being a problem provide a solution which allows one thousand million people to make a living and to get by. Instead of ignoring this process, it would be sensible to try and provide some guidance. Joan MacDonald, director of SELAVIP, recently commented in Madrid that: "What we need are architects who will teach others to be architects. I have never known a better professional for looking further than the case in hand and making a connection between situations". The formal city has much to learn from the informal city where, for example, children still play in the street. "It is not a certainty that the poor will want a block and a shopping Centre”.

The vibrant movement of the informal city (settlement, expansion, densification) follows along the lines of the formal city and this formal-informal duality gives rise to a mutant city, with traces of both these realities, where limits, as in their borders and frontiers, are becoming increasingly blurred.

The formal-informal obviousness is broken down to form a complex and conflictive scenario which in addition to generating urban inefficiency, brings with it enormous environmental and social imbalances.

By observing in a more comprehensive, open and innovative manner the morphological spatial, functional and social relations of the metropolis as in the new critical geography put forward by Raquel Tardin, we will be able to obtain further clues to reading and understanding the informal city in this complex combination of formal and informal. This new perspective is extremely useful when proposing innovative actions which respect territorial differences, while maintaining a strong component of social commitment. Such actions should be incorporated in a network of plural metropolitan relations based on dialogue and exercise of citizenry in its widest sense [7].

\section{The dynamics of social inclusion: areas of identity}

Living conditions are terrible. There is a shortage of water and electricity. Houses are built of timber and clay and have no bathrooms. There are over 400,000 people living in the Kibera ghetto. When designing the project in 2009 JR explained that his work method evolved after a woman in the favela told him that "we are hungry, hungry for culture, we need culture we need art". JR's project carried out in the largest and most conflictive shanty town in Africa focused on covering the roofs of some houses to prevent leaks and at the same time to create places from where they could be recognised. So was combined a protest project with a project identity-based.

By definition an architect is an agent of change, a transforming element of society and its environment. Architecture in this sense cannot remain passive. Given this complex development of urban movements, the most significant action by architects is to attempt to take up a position. To seek elements of verification, to provide answers. Rem Koolhaas speaks of the importance of this endeavour using terms which little by little have gained credence such as "cityness", "gentrification", "civility", as used by Sassen [8] or Sennett. 
However the real problem that architecture faces is a problem of "identity" of "authenticity" [9].

The dies of social and cultural responsibility are returning to the vanguard of contemporary architecture. It is now possible to find large libraries in deprived areas, transport systems such as trams or cable cars in marginalised areas, or museums in informal settlements. Through actions which recognise and legitimise the potentialities of urban informality, architects have begun to adopt the informal city as a new paradigm. Together with the increasing attraction of this idea, analyses of the main questions and issues as well as the short and long term results of these actions are critical. When addressing the need for action from the perspective of identity, we need to realise that the informal city is not disconnected from the formal city. Quite the contrary in fact, informality is not a product but rather a process constantly seeking to change and redefine relations with the formal.

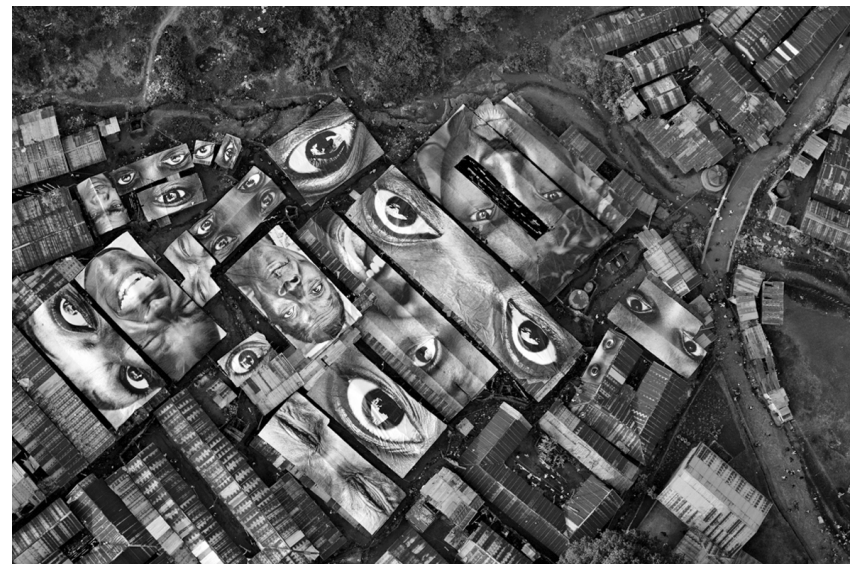

Figure 3: $\quad$ Kibera, project Kenya, JR.

If the informal city or society is viewed as a product or as a mere question of form and distribution, any action will run the risk of ignoring critical factors relating to these processes. The importance of linking design with sociological analyses and political decisions is in this sense essential.

One of the greatest obstacles for many practices and projects relating to informality is a failure to integrate with the policies of government agencies. Another is to obviate the population's need for identity.

Within the context of the informal city where options are limited and where informality is at times the only possibility for survival or resistance, action and focus on design mean opportunities for the local population to obtain recognition and to claim their rights to the city. However we need to understand and evaluate the impact and value of using strategies and actions to avoid falling into the trap of adopting an image of social righteousness instead of addressing the social and economic realities of everyday life [10]. 
Contemplating these issues in 1961, Jane Jacobs highlighted the importance of proposing an inclusive city model, in particular in the final chapter in her book The Death and Life of Great American Cities where she states: "regarding the problem of understanding cities I believe that the most important lines of thought are as follows: 1 Thinking about processes; 2. Working in inductive mode by reasoning from the particular to the general, rather than the other way round; 3. Seeing "non quantifiable" clues involving minor examples which show the way in which things are operating on a greater scale and more representative "averages"” [11].

That is, proposing work which will enable more complex planning programmes to be developed on the basis of areas of identity.

What is the value in all this fro architects? Generally architects are choosing to work with instead of against informal architecture and they are the first to consider the wishes and choices of the marginalised citizens in designing their surroundings.

Improvements in infrastructures and public art projects (such as the work of the Urban Think Tank or JR) have contributed to removing some of the stigma attached to these urban areas and their inhabitants which at times can amount to complete obliviousness to their conditions.

Nevertheless, in this acceptance of informality it is all too easy to forget that informal living means living dangerously. Informality is not a solution or an end in itself but rather a new set of conditions or challenges.

We should congratulate these communities on their resistance and strength, and support the investments that residents have made in building their environment, often against all prognoses However, there is not much that just one person can do. The residents of informal areas usually invest in the interior of their homes, leaving the exterior unfinished, which presupposes an indicator of the limited scope and resources available to residents to formalise their communities. Construction is slow, difficult and costly for residents. Beyond their own house or perhaps a small business, residents have scant capacity to give shape to their public spaces or to provide the extremely necessary services such as the caring about transport, education and health. Informality poses a dilemma as it suggests creative and innovative solutions but at the same time it means a loss of security and protection. It is too easy to fall into the trap of forgetting that informality is a substitute for safe and prosperous conditions of work and life. As Ricky Burdett has so eloquently reminded us, joining the physical to the human and social is a means for achieving wider goals of the city [12]. In essence it determines whether or not we grow economically in a sustainable and inclusive manner.

\section{On urban acupuncture: strategic proposals}

Around sixty percent of the population of Caracas live in informal settlement son the hillsides surrounding the city however due to their illegal status these areas have not been formally linked to the public transport service. The architects Alfredo Brillembourg and Hubert Klumpner, proposed building a public cable 
car system, Metrocable, connecting two neighbourhoods. Some elements of the highly politicised project have been altered; however, the project continues to contribute to promoting access to culture and gradual changes in the social structure of Caracas.

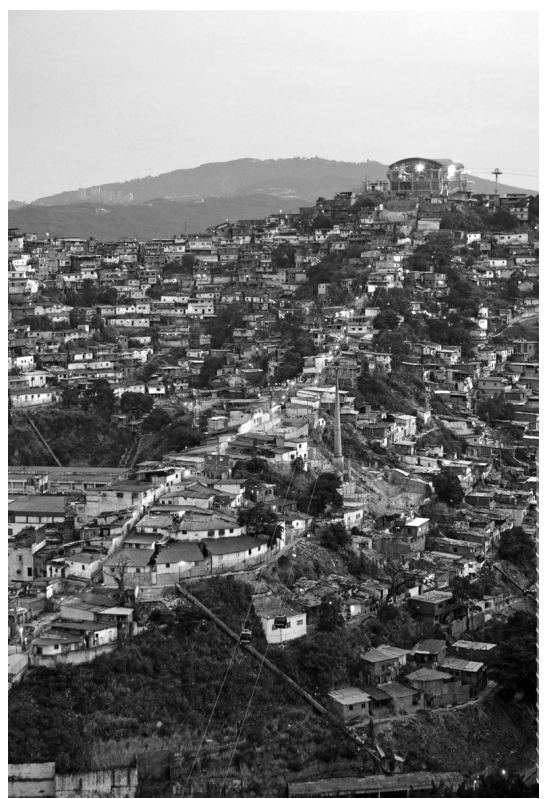

Figure 4: $\quad$ Metrocable project, Caracas, Urban Think Tank.

In the exhibition commissioned by MOMA entitled 'Small Scale, Big Change: New Architectures of Social Engagement' (October 3, 2010 to January 3 , 2011) eleven construction projects from the five continents were presented showing innovative and inclusive architectural projects for marginalised communities [13]. From Alejandro Aravena to Diébédo Keré,and from Jorge Mario Jáuregui to Michael Maltzán. The architects have responded to the functional needs of their projects however they have also endeavoured to cause a general positive effect on the communities in which they work. In this way they act as collaborators in the social economic and political transformation of the places where the project is implemented. In addition to new modes of participatory design, the projects exhibited incorporate pioneering solutions for specific places testing ecological and socially sustainable architectural practices. Populations and groups who hitherto have rarely attracted the attention of architects participate in the development and innovation incorporated in projects which are worthy of a wider attention. The renewal of these architects' commitment and that of many of their colleagues to create socially responsible architecture presupposes a radical change in the way that the city and architecture is understood. In general we call this "acupuncture" of projects which are limited in their action and effects however with an extraordinary scope 
in terms of the repercussions of the proposals. The success of these projects is based on the possibility of providing communities not only with physical spaces but also with opportunities for self determination and a greater sense of identity. These proposals provide a catalyst for change. Their methods of integration could serve as the model for development of the profession in this Era of Cities [14].

In the contemporary context, where planning regulations are becoming increasingly rigorous, it is essential to consider more proactive and smaller scale mechanisms in order to regulate the form that the city takes. The concept of "urban acupuncture" implies that considerably smaller urban strategies lead to a series of processes which have effect on a much greater scale that that of their original scope. The idea of projects such as Favela-Bairro, based on the connectivity of public space is powerful in this respect, namely minor seemingly irrelevant actions set of unexpected complex and interesting processes which provide much more satisfactory results than if they had derived from large scale urban planning. In the process of producing new narratives fro reconstructing the city, sectors which are normally excluded not only are incorporated in the formal city but their inhabitants become active participants in the city. Thinking of the informal city in this way means recovering the discourse of open form.

Within this framework of thought, recovery of cities such as Medellín or Bogotá in Colombia illustrates the social capacity of urban development proposed as a tool for mitigating serious problems of inequality and segregation, and to connect, integrate and coordinate the city through an instrument of social and physical inclusion. Strategic architecture and urban development have been the main tools used in working with the community and implementing a process for the recovery of the city's critical neighbourhoods.

In Bogotá through a detailed study of the programme, the city attempted to construct new networks of public facilities for low income districts located strategically throughout the territory. From a social perspective the purpose was to identify processes and dynamics emerging from the community and from the different agents working to encourage participation and local appropriation before during and after the activities. In Medellín there was a greater concentration in specific territories with a singular architecture, highlighting the value of the "protagonism" of the pieces and their connections. This approach differs from the previous idea of Bogotá, where attention was focused more on transversal systems or networks including transport systems such as the TransMilenio, or pedestrian paths and bicycle lanes, while always placing emphasis on the quality of new public buildings which act as icons in reinventing the image of the city. Despite their different approaches the final result was similar in both cities. In the last 15 years both have undergone a spectacular process of democratisation which has given rise to a high level of social integration. In both cases the provision of quality infrastructures and urban services in the poorest most violent districts has imbued residents with a sense of equality and a feeling of belonging to their very own city.

Thus, the problems associated with large scale urban planning have created a renewed interest in the small scale project. The most recent ventures and actions 
in Latin America, Africa and some parts of Asia have favoured the "urban acupuncture" approach. This suggests an alternative to "urban surgery". Instead of seeing the urban body as a composition of parts and organs, the idea of urban architecture sees it instead as a continuous nervous system which should only be treated at a local level in order to "release energy" which will then have effects on the whole.

\section{Conclusion}

In a globalised world ten "planet of future cities" collides head on with the "planet of misery cities" [15]. The law of the city, at least in terms of current conditioning $\mathrm{f}$ actors is too restricted in the majority of cases to a small political and economic elite who find increasingly favourable conditions for creating cities to suit their own interests. During the $21^{\text {st }}$ century strong and consistent opposition to such behaviour is required which will be able to provide stable and constitutional policies. The general dynamic of this Formal Urban Era should be that of inclusion. Dedication and tenacity is required to close the gap between formal and informal cities. A city that covers the distance between the future city and the city of misery need not be a fiction; it is based on a realistic assessment of the potential of urban processes to profit from future opportunities and to satisfy the aspirations of the community as a whole.

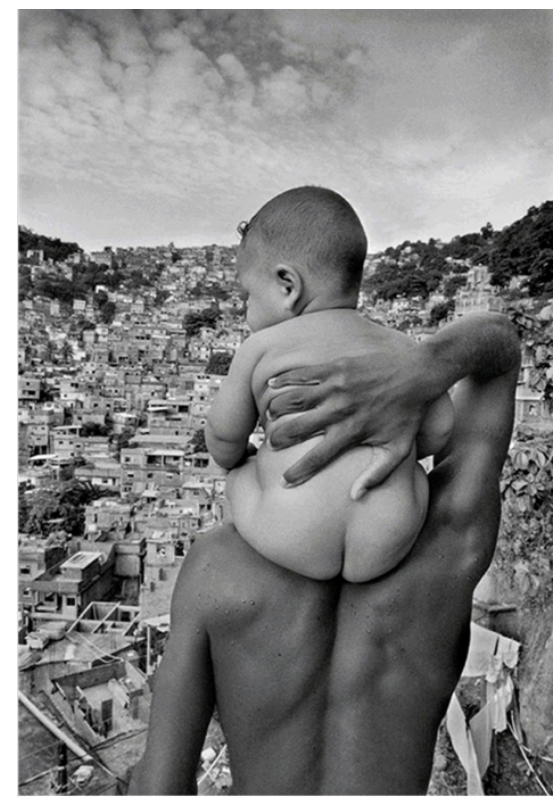

Figure 5: Favela Rocinha, Río de Janeiro, André Cypriano. 
Rocinha is one of the most dangerous and violent Favelas in Brazil. When photographing the Favela, André proposes visualising the social conflict in these areas which traditionally were left out of political and urban planning processes. He explains the need to include all these people in the decision making process and in the management of the city, asking what we can bring as outsiders in these situations of urban marginalisation.

In this way integrating displaced persons into urban life mans improving quality of life investing in training and educating human capital, promoting economic opportunities, opening channels for political participation and developing cultural inclusion.

In fact, these points should be a call to our generation to construct a different world of urban opportunities and open possibilities. This Urban Era calls for us to act with vision, imagination and confidence.

\section{References}

[1] United Nations Human Settlements Programme (UN-HABITAT). (2011). State of the World's Cities 2010/2011: Bridging The Urban Divide. London: Earthscan.

[2] Calatrava, J., \& González Alcantud, J.A. (2007). La Ciudad: Paraíso y Conflicto. Madrid: Abada.

[3] Parker, R. (1967). On Social Control and Collective Behavior. Chicago: University of Chicago Press.

[4] Harvey, D. (Sep/Oct 2008) The Right to the City. New Left Review, nº53, pp. 23-40. ISSN: 0028-6060

[5] Perán, M. (2008). Post-it City: Ciudades Ocasionales. Barcelona: Centre de Cultura Contemporánea.

[6] Balbo, M. (Jan/Feb 1993) Urban Planning and the Fragmented City of Developing Countries, Third World Planning Review, vol XV, pp. 32.ISSN: 0042-0980.

[7] Wright, H. (2008). Instant Cities. London: Black Dog.

[8] Sassen, S. (1991). The Global City: New York, London, Tokyo. New Jersey: Princeton University Press.

[9] Koolhaas, R., \& Boeri, S., \& Kwinter, S. (2002). Mutations. Barcelona: Actar.

[10] Muñoz, F. (2010). Urbanalización: Paisajes comunes, lugares globales. Barcelona: GG.

[11] Jacobs, J. (2011). The Death and Life of Great American Cities Madrid: Capitan Swing Libros.

[12] Burdett, R., \& Sudjic, D. (Eds.). (2007). The Endless City: The Urban Age Project by the London School of Economics. London: Phaidon Press Ltd.

[13] Lapik, A. (2010). Small Scale, Big Change: New Architectures of Social Engagement. New York: MoMa.

[14] Sassen, S. (May/Jun 2011) When Cities Become Strategic. Architectural Design, vol81, nº3, pp. 124-128. ISSN: 0003-8504.

[15] Davis, M. (2008). Planeta de Ciudades Miseria. Madrid: Foca/Akal. 